\title{
Platelet aggregability during the first two years of Type 1 (insulin-dependent) diabetes mellitus in children
}

\author{
A.M.Kobbah, U.Ewald and T. Tuvemo \\ Department of Paediatrics, Akademiska Hospital, Uppsala, Sweden
}

\begin{abstract}
Summary. Platelet aggregation in response to collagen, adenosine diphosphate and arachidonic acid was studied prospectively in 30 children with Type 1 (insulin-dependent) diabetes mellitus. The studies began on admission to hospital and continued throughout the two years following diagnosis. The results were compared with those in 44 healthy control children. Collagen-induced aggregation was significantly decreased in the diabetic children on admission in comparison to the healthy children. In contrast, the aggregation induced by adenosine diphosphate $(1.1 \mu \mathrm{mol} / 1, p<0.05)$ and arachidonic acid $(0.25 \mathrm{mmol} / 1, p<0.05)$ was increased on admission. The magnitude of the platelet shape change after adenosine diphosphate stimulation was small at the onset of the disease
\end{abstract}

but was significantly increased towards normal during the two years of follow-up. On admission, the primary wave aggregation induced by adenosine diphosphate was positively and significantly correlated to some of the lipoprotein fractions that were disturbed at that time, especially triglycerides in high-density lipoproteins. After two years of treatment the platelet aggregability in the diabetic children had been restored to normal.

Key words: Type 1 (insulin-dependent) diabetes mellitus, platelet aggregation, collagen, adenosine diphosphate, arachidonic acid.
An abnormal interaction between the platelet and blood vessel wall contributing to microangiopathy in Type 1 (insulin-dependent) diabetes mellitus has been recently suggested [1-4]. In cross-sectional studies on adult subjects with Type 1 diabetes and investigations on experimental diabetes in animals, several authors have convincingly demonstrated functional abnormalities of platelets in vitro $[1,4-9]$ and in vivo as measured by platelet survival and plasma beta-thromboglobulin levels $[2,7,10,11]$. The typical functional aberration in vitro is an increased sensitivity to aggregating agents such as collagen, adenosine diphosphate (ADP) and arachidonic acid (AA), whereby the so called irreversible phase or the release reaction is enhanced, which can be explained by the finding of an increased production of proaggregatory eicosanoid metabolites in platelets from patients with Type 1 diabetes [12].

There is also convincing evidence of altered endothelial function in Type 1 diabetes, with a decreased production of deaggregatory substances e.g. prostacyclin [7-9, 13], an increased formation of von Willebrand factor $[1,10]$ and decreased release of plasminogen activator $[14,15]$.
The relationship between the platelet and endothelial functional abnormalities in Type 1 diabetes is controversial. It has been debated, for instance, whether the platelet aberrations are secondary to the endothelial dysfunction or vice versa [1] and even if they are totally independent of each other.

As more marked platelet changes have been found in Type 1 diabetic patients with pronounced vascular disease, the disturbed platelet function might be a consequence of the vascular disorder rather than the reverse. The observed changes in carbohydrate, protein, metal ion and lipid metabolism [16-23] in Type 1 diabetes have also been proposed as causes of the increased platelet aggregability, as have circulating immune complexes [24], hormonal aberrations and changes in the activities of certain enzymes, e.g. phospholipase $A_{2}$ [7].

Children acquiring Type 1 diabetes as a rule have no vascular disease, and furthermore they lack factors that influence the platelet tests such as ageing, drug intake and smoking and therefore represent an ideal experimental group in this respect. In a cross-sectional study $[25,26]$ it was found that children with Type 1 diabetes of a 2-8 year cluration exhibited both increased 
$\triangle O D \%$

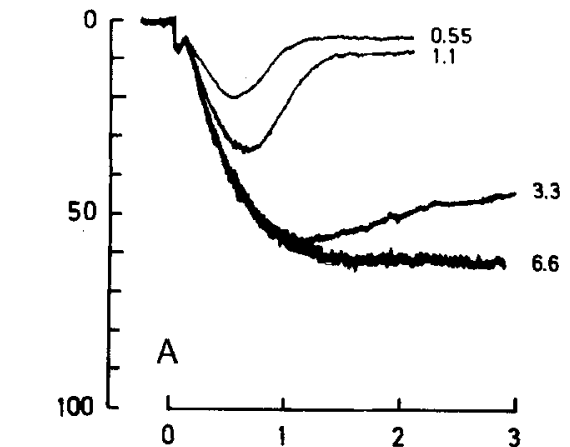

$\triangle O D \%$

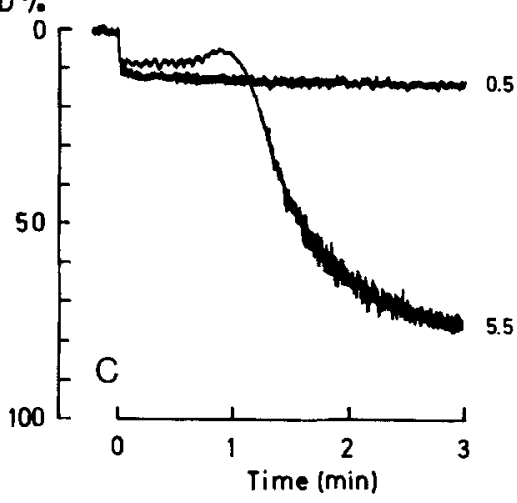

$\triangle O D \%$
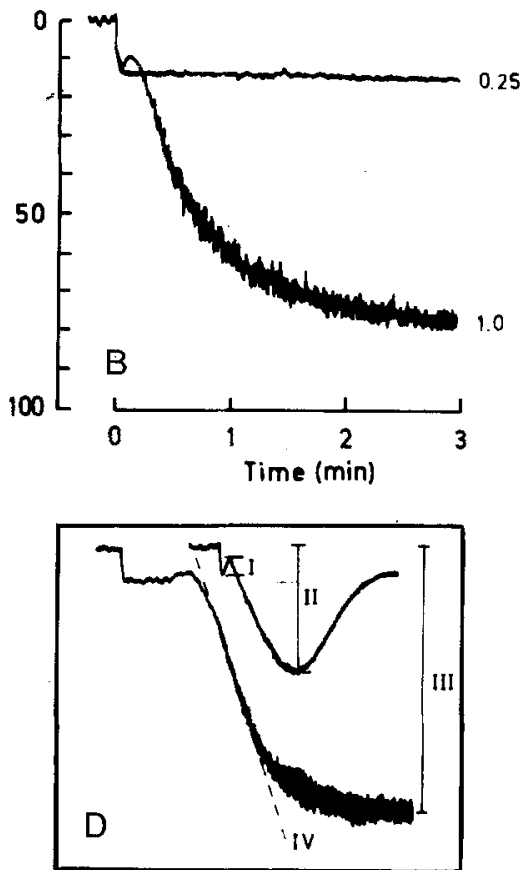

Fig. 1 A-D. Typical recordings of platelet aggregation induced by aggregating agents: A Adenosine diphosphate (ADP) $0.55,1.1,3.3,6.6 \mu \mathrm{mol} / 1$, $B$ arachidonic acid (AA) 0.25 , $1.0 \mathrm{mmol} / 1$, C collagen (COL) 0.5 , $5.5 \mathrm{mg} / 1, \mathbf{D}$ evaluation variables: $\mathrm{I}=$ platelet shape change (ADP); $I I=$ primary wave aggregation (ADP); III = aggregation at $3 \mathrm{~min}(\mathrm{ADP}, \mathrm{AA}$, $\mathrm{COL}) ; \mathrm{IV}=$ aggregation velocity (AA, COL) platelet aggregability in vitro and a reduced vasodilative capacity in vivo. To further elucidate the hypothesis of a disturbance of the platelet/blood vessel wall interaction in the pathogenesis of diabetic angiopathy, we designed a study in which a population-based cohort of newly diagnosed children with Type 1 diabetes were investigated prospectively for disorders of platelet or vascular function from the day of diagnosis before the very first insulin injection and then at 6,12 and 24 months. The aim of this work was to investigate the platelet sensitivity to aggregating agents during the first two years of Type 1 diabetes and to try to relate any abnormalities to disturbances in carbohydrate, protein, metal ion and lipid metabolism.

\section{Subjects and methods}

All children $(n=36)$ in the county of Uppsala, Sweden, with Type 1 diabetes mellitus newly diagnosed between December 1982 and October 1984 were included prospectively in a study on early vascular and platelet dysfunction. Patients under 3 years of age were excluded from those parts of the study in which repeated venepuncture was necessary. Thirty children of ages 3-15 years (mean $=9.3$ ), 19 girls and 11 boys, were available for the study of platelet aggregability. The patients were investigated on admission $(n=19)$ to hospital before the very first insulin injection, and followed up six months $(n=27)$, one year $(n=30)$ and two years $(n=28)$ after diagnosis. On all four occasions 18 children were investigated. Any samples showing coagulation or haemolysis during sampling, and samples from patients who had taken salicylates in the previous two weeks were discarded. This was the reason for the small number of children with diabetes investigated on admission. Forty-four healthy children ( 27 girls and 17 boys) aged 4-16 years $($ mean $=11.5)$ ( 20 relatives and neighbours of hospital staff and 24 peers of the children in the study group) served as control subjects. They were investigated once at the 24 month follow-up of their peers with Type 1 diabetes. Two control children were excluded on account of salicylate intake. After fasting all children visited the clinic voluntarily to offer a blood specimen. All blood samples were taken before insulin injection and breakfast at $07.00-08.00$ hours, except those samples taken on admission for children with Type 1 diabetes. In those children, blood samples were taken immediately after the diagnosis of diabetes, before insulin was given. In all subjects, an antecubital vein was punctured with a 21 Gauge cannula, and $9 \mathrm{ml}$ of free-flowing blood was collected without venous stasis into a plastic syringe containing $1 \mathrm{ml}$ of $3.8 \%$ sodium citrate for platelet aggregation studies. The citrated blood was immediately prepared and platelet rich plasma (PRP) and platelet poor plasma (PPP) were obtained by centrifugation at $20^{\circ} \mathrm{C}$ at $150 \times g$ for $15 \mathrm{~min}$ and $1,500 \times g$ for $10 \mathrm{~min}$, respectively. The platelet count in PRP, which was not significantly different between the groups, was determined on a Thrombocounter $\mathrm{C}$ (Coulter Electronics, Hialeah, Fla, USA), and was adjusted to $300 \times 10^{9} / 1$ by the addition of homologous PPP. The adjusted PRP was kept in plastic tubes covered with para film at room temperature and the aggregation studies were all started within $40 \mathrm{~min}$ after sampling. Platelet aggregation was studied by the turbidimetric method of Born on a Payton 600 aggregometer (Payton Associates, Scarborough, Ontario, Canada) at $37^{\circ} \mathrm{C}$, with stirring at $900 \mathrm{rev} / \mathrm{min}$ [27]. The changes in optical densities ( $\triangle O D$ ) were continuously monitored during and after addition of $50 \mu \mathrm{l}$ of aggregating agents in $250 \mu l$ of specimen. The aggregation-inducing agents used were collagen Horm (Hormonchemie, Munich, FRG) in concentrations of 0.5, 1.0 and $5.5 \mathrm{mg} / 1$ (final concentration in the cuvette), ADP (Sigma, St. Louis, Mo, USA) in concentrations of $0.55,1.1,3.3$ and $6.6 \mu \mathrm{mol} / 1$ and AA (Sigma) in concentrations of 0.25 and $1.0 \mathrm{mmol} / 1$. In the recordings the percentual changes in the $\triangle \mathrm{OD}$ (PRP 100\% PPP 0\%) of the shape change, the primary wave aggregation and the aggregation after $3 \mathrm{~min}$ were measured after addition of ADP (Fig. $1 \mathrm{~A}$ and D). After collagen and AA stimulation the aggregation (after $3 \mathrm{~min}$ ) and the aggregation velocity (measured as the deflection angle) were also measured (Fig. 1 B, C and D).

The children with diabetes were treated with i.v. insulin infusion for the first 48-72 h (except three patients who received s.c. injections from the start) and then with two doses per day of combinations of regular (Actrapid, Novo, Copenhagen, Denmark - 21 patients December 1982 - April 1984; Humulin Regular, Eli Lilly, Indianapolis, 

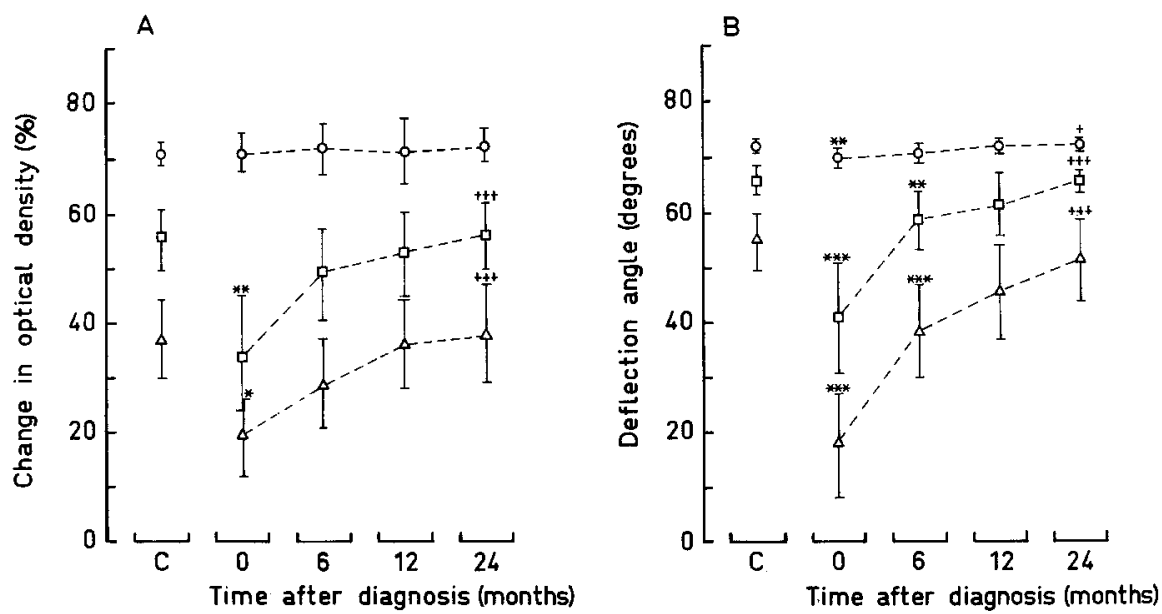

Fig. $2 \mathrm{~A}$ and B. Platelet aggregation after $3 \mathrm{~min}(\mathbf{A})$ and aggregation velocity (B) induced by collagen $(\Delta=0.5, \square=1.0$, $\mathrm{O}=5.5 \mathrm{mg} / \mathrm{l}$ ) in Type 1 (insulin-dependent) diabetic and control children (C) (mean $\pm 95 \%$ confidence intervals). $*=p<0.05, * *=p<0.01, * * *=p<0.001$ in comparison with the control group (C). $+=p<0.05,++=p<0.01$, $+++=p<0.001$ in comparison with time of admission

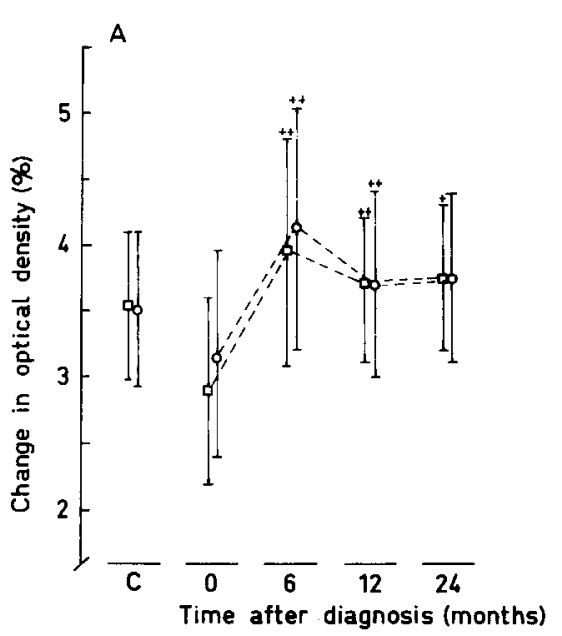

Fig. 3 A-C. Shape change (A), primary wave aggregation (B) and aggregation after $3 \mathrm{~min}(\mathrm{C})$ induced by adenosine diphosphate (ADP) $(-=0.55, \Delta=1.1, \square=3.3, O=6.6 \mu \mathrm{mol} / 1)$ in Type 1 (insulin-dependent) diabetic and control children (C) (mean $\pm 95 \%$ confidence intervals). ${ }^{*}=p<0.05$, in comparison with the control group (C). $+=p<0.05,++=p<0.01$, in comparison with time of admission

Ind., USA - 9 patients April 1984 - October 1984) and intermediate (Monotard in the former group and Humulin NPH in the latter group) insulins. During the period of the study, a change was made to three insulin injections per day in five patients, and one patient received four injections per day after one year of treatment. The diabetic diet followed the current Swedish regimen, consisting in a regulated diet intended to supply $50-55 \%$ of the energy intake from carbohydrate, $30-35 \%$ from fat and $15-20 \%$ from proteins. The diet should be rich in polyunsaturated fatty acids and the carbohydrates should have a high fibre content. According to an earlier study our diabetic children adhere relatively well to this recommendation, except for fat intake which was slightly higher than that recommended [28]. Fasting plasma glucose and $24 \mathrm{~h}$ urine glucose excretion were determined by routine methods. $\mathrm{HbA}_{1}$ was measured up to April 1984 and $\mathrm{HbA}_{1 \mathrm{c}}$ from April 1984 to April 1985 by standard microcolumn chromatography (Biorad, Richmond, Calif, USA). After April $1985 \mathrm{HbA}_{1 \mathrm{c}}$ was measured by FPLC (Pharmacia, Uppsala, Sweden). All values have been recalculated and expressed as $\mathrm{HbA}_{1 \mathrm{c}}$. None of the diabetic or control children included in the study had received any platelet-inhibiting drugs during the two weeks preceding the platelet aggregation investigations.

Serum albumin was measured by a bromcresol green method, prealbumin and orosomucoid were determined by a polymer enhanced immunoturbidimetric method, and the concentrations of calcium, magnesium and zinc in serum were measured by atomic absorption spectrometry [29]. Triglyceride (TG) and cholesterol concentrations were assayed in serum and in the isolated lipoprotein fractions by enzymatic methods, and the concentrations of serum apolipoproteins (apo) A-I, A-II and B were determined by turbidimetry [23].

The study was approved by the Ethics Committee of the Medical Faculty, University of Uppsala, Uppsala, Sweden.

\section{Statistical analysis}

Wilcoxon's signed rank test was used to test differences between groups of subjects. Differences between repeated experiments in the 18 patients where complete longitudinal data were obtained were tested by paired Student's $t$-tests. Correlations within a group were analysed by Spearman's coefficient of correlation $\left(r_{\mathrm{s}}\right)$. Correlations of $p<0.01$ were considered as statistically significant.

\section{Results}

\section{Platelet aggregability in Type 1 diabetic children compared with control children}

Collagen. In the children with Type 1 diabetes, platelet aggregation ( $3 \mathrm{~min}$ ) induced by low-dose collagen $(0.5$, $1.0 \mathrm{mg} / 1)$ was lower at the time of diagnosis than in healthy control children $(p<0.05 ; p<0.01$, respective- 

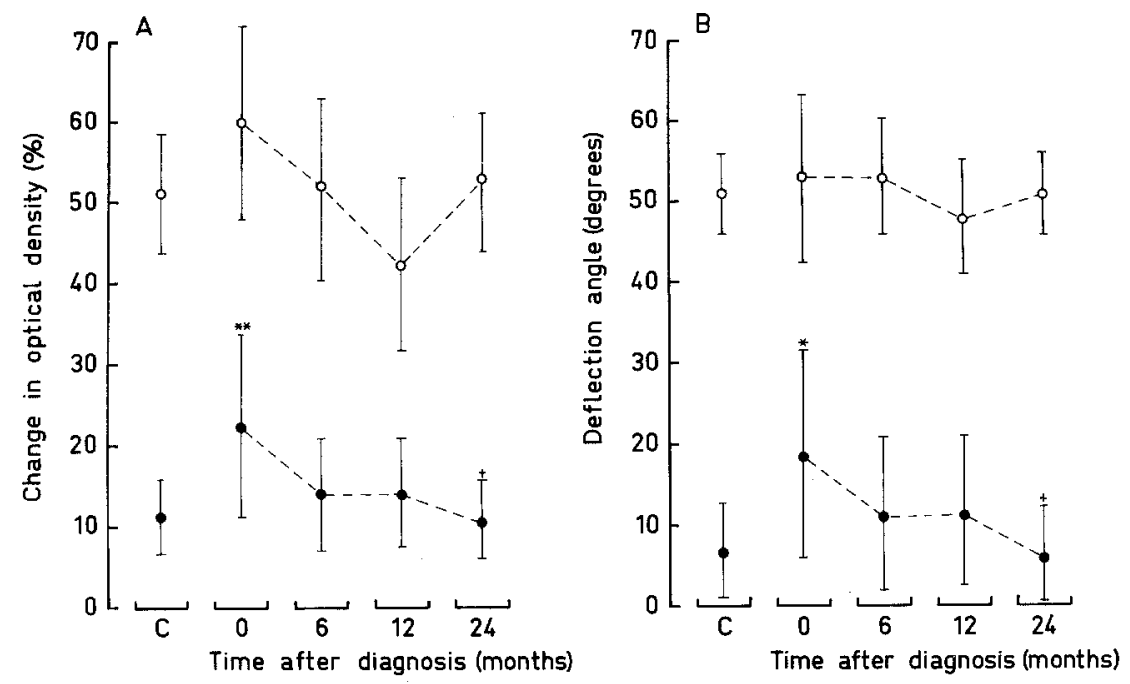

Fig. $4 \mathrm{~A}$ and B. Platelet aggregation after $3 \mathrm{~min}$ (A) and aggregation velocity $(\mathbf{B})$ induced by arachidonic acid (AA) $(-=0.25, O=1.0 \mathrm{mmol} / \mathrm{l})$ in Type 1 (insulin-dependent) diabetic and control children (C) (mean $\pm 95 \%$ confidence intervals). $*=p<0.05, * *=p<0.01$, in comparison with the control group (C). $+=p<0.05$, in comparison with time of admission ly). After 6,12 and 24 months of insulin treatment, no significant difference from the control children was noted. The platelet aggregation after the addition of the high collagen dose $(5.5 \mathrm{mg} / \mathrm{l})$ did not differ from that in the healthy control group (Fig. 2A). The aggregation velocity induced by collagen $(0.5,1.0 \mathrm{mg} / \mathrm{l})$ was significantly reduced on admission (both $p<0.001$ ) and after 6 months ( $p<0.001$ and $p<0.01$, respectively) in comparison with that in healthy control children. After 1

Table 1. Insulin treatment and carbohydrate control in the Type 1 (insulin-dependent) diabetic children studied prospectively during the first two years of their disease. Means $\pm S D$ are given for total insulin/day, insulin/ $\mathrm{kg}$ body weight, $\mathrm{HbA}_{1 \mathrm{c}}$ and plasma glucose, and medians and quartiles for $24 \mathrm{~h}$ urine glucose excretion

\begin{tabular}{|c|c|c|c|c|c|}
\hline (months) & $\begin{array}{l}\text { Total } \\
\text { insulin/day } \\
\text { (IU) }\end{array}$ & $\begin{array}{l}\text { Insulin/ } \\
\text { kg body } \\
\text { weight } \\
\text { (IU) }\end{array}$ & $\mathrm{HbA}_{1 \mathrm{c}}$ & 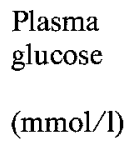 & $\begin{array}{l}24 \text { h urine } \\
\text { glucose } \\
\text { excretion } \\
\text { (mmol) }\end{array}$ \\
\hline 0 & - & - & $10.0 \pm 1.9$ & $18.9 \pm 9.9$ & $378(89-823)$ \\
\hline 6 & $21.1 \pm 10$ & $0.6 \pm 0.2$ & $6.2 \pm 1$ & $7.0 \pm 3.6$ & $0(0-49)$ \\
\hline 12 & $26.5 \pm 11.6$ & $0.7 \pm 0.2$ & $7.0 \pm 1.3$ & $7.0 \pm 2.9$ & $5(0-36)$ \\
\hline 24 & $37.0 \pm 16.0$ & $0.8 \pm 0.2$ & $7.7 \pm 2.0$ & $10.4 \pm 5.2$ & $70(3-167)$ \\
\hline
\end{tabular}

Table 2. Significant relationships Type 1 (insulin-dependent) between platelet aggregation and lipoprotein lipid fractions in newly diagnosed diabetic children on admission

\begin{tabular}{lllll}
\hline $\begin{array}{l}\text { Stimulating } \\
\text { substance } \\
\text { (mmol/1) }\end{array}$ & $\begin{array}{l}\text { Platelet } \\
\text { aggregation }\end{array}$ & $\begin{array}{l}\text { Lipoprotein } \\
\text { fraction }\end{array}$ & $\begin{array}{l}\text { Correla- } \\
\text { tion co- } \\
\text { efficient }\end{array}$ & $p$ value \\
\hline ADP 0.55 & Primary wave & : VLDL TG & $r=0.64 ;$ & $p<0.01$ \\
ADP 0.55 & Primary wave & : VLDL Chol & $r=0.72 ;$ & $p<0.01$ \\
ADP 1.1 & Primary wave & : VLDL Chol & $r=0.70 ;$ & $p<0.01$ \\
ADP 1.1 & Aggregation (3 min) & : VLDL Chol & $r=0.62 ;$ & $p<0.01$ \\
ADP 0.55 & Primary wave & : HDL TG & $r=0.78 ;$ & $p<0.001$ \\
ADP 1.1 & Primary wave & : HDL TG & $r=0.88 ;$ & $p<0.001$ \\
ADP 3.3 & Primary wave & : HDL TG & $r=0.65 ;$ & $p<0.01$ \\
ADP 0.55 & Primary wave & : serum TG & $r=0.62 ;$ & $p<0.01$ \\
ADP 1.1 & Aggregation (3 min) & : serum TG & $r=0.64 ;$ & $p<0.01$ \\
\hline
\end{tabular}

$\mathrm{VLDL}=$ very low density lipoprotein, $\mathrm{HDL}=$ high density lipoprotein, $\mathrm{ADP}=$ adenosine diphosphate, $\mathrm{TG}=$ triglyceride, $\mathrm{Chol}=$ cholesterol and 2 years of treatment, there was no significant difference from the control children. The aggregation velocity after the addition of collagen $5.5 \mathrm{mg} / 1$ was significantly lower than that in the control children at onset of the disease $(p<0.01)$, but not later (Fig. 2B).

Adenosine diphosphate. The magnitude of the shape change induced by ADP ( 3.3 and $6.6 \mu \mathrm{mol} / \mathrm{l})$ was relatively small at diagnosis of Type 1 diabetes but was not significantly smaller than in the healthy control children (Fig. $3 \mathrm{~A}$ ). The primary wave aggregations induced by ADP $(0.55,1.1,3.3$ and $6.6 \mu \mathrm{mol} / \mathrm{l})$ were slightly higher at diagnosis of Type 1 diabetes than in healthy control children, but this difference was only significant in the test with ADP $1.1 \mu \mathrm{mol} / 1$ (Fig. $3 \mathrm{~B}$ ). The platelet aggregation ( $3 \mathrm{~min}$ ) induced by ADP did not change significantly from that in healthy control children (Fig. 3C).

Arachidonic acid. On admission, the platelets of the children with Type 1 diabetes showed an increased response to AA at the lower concentration $(0.25 \mathrm{mmol} / \mathrm{l})$ compared with the platelets of control children ( $3 \mathrm{~min}$ aggregation $p<0.01$; aggregation velocity $p<0.05)$. At the higher concentration $(1.0 \mathrm{mmol} / 1)$ there was no such difference (Fig. 4A, B).

\section{Longitudinal changes in platelet aggregability in Type 1 diabetes}

Collagen. The aggregations and aggregation velocities induced by low doses of collagen $(0.5,1.0 \mathrm{mg} / 1)$ increased significantly from time of admission to 24 months (Fig. 2A, B) (all $p<0.001)$. The aggregation velocity after stimulation by a high dose of collagen $(5.5 \mathrm{mg} / 1)$ also increased slightly $(p<0.05)$, but the aggregation ( $3 \mathrm{~min}$ ) was unchanged (Fig. $2 \mathrm{~A}$ ).

Adenosine diphosphate. The magnitude of the platelet shape change induced by $\operatorname{ADP}(3.3$ and $6.6 \mu \mathrm{mol} / 1)$ was 
larger after 6 and 12 months of Type 1 diabetes mellitus (all $p<0.01$ ) than at diagnosis (Fig. $3 \mathrm{~A}$ ). The primary wave induced by ADP was high on admission and after 6 months, but decreased gradually from 6 to 24 months (Fig. $3 \mathrm{~B}$ ). The platelet aggregation $(3 \mathrm{~min}$ ) induced by ADP did not change significantly during the observation period (Fig. 3C).

Arachidonic acid. The maximal aggregation and aggregation velocity induced by a low dose of AA $(0.25 \mathrm{mmol} / 1)$ decreased from admission to follow-up 2 years after diagnosis $(p<0.05)$, while the aggregation induced by the higher dose AA $(1.0 \mathrm{mmol} / \mathrm{l})$ did not change significantly (Fig.4A, B).

\section{Platelet aggregability - its relationship to sex and age}

The platelet aggregability did not differ significantly between males and females with diabetes either on admission or later, or between male and female control children, after stimulation by collagen, ADP or AA. There was no significant difference between Type 1 diabetic or control children below the age of 10 years and those above this age.

\section{Platelet aggregability - its relationship to diabetes treatment and control}

The carbohydrate indices improved significantly during the first months of treatment and deteriorated slightly after 6 months (Table 1). On admission, ADP $(3.3 \mu \mathrm{mol} / 1)$-stimulated primary wave aggregation and aggregation after $3 \mathrm{~min}$ correlated to $24 \mathrm{~h}$ urine glucose excretion $(r=0.67, p<0.01 ; r=0.62, p<0.01$, respectively (Fig. $5 \mathrm{~A}$ ). After 6 months, the magnitude of platelet shape change induced by ADP at $6.6 \mu \mathrm{mol} / 1$ correlated negatively to urine glucose excretion $(r=0.50, p<0.01)$ and tended to correlate (negatively) to $\mathrm{HbA}_{1 \mathrm{c}}(p<0.05)$. With these exceptions, the platelet aggregation induced by ADP, collagen and AA in all doses was not significantly correlated to any parameters of carbohydrate control measured on any occasion or to insulin dosage per $\mathrm{kg}$ body weight.

\section{Platelet aggregability - its relationship to proteins, metals and lipids}

ADP-stimulated aggregation correlated positively to several lipoprotein fractions, especially TG-containing lipoproteins, on the day of admission (Fig. $5 \mathrm{~B}$ and C, Table 2). After one year serum orosomucoid was negatively correlated to the ADP-induced primary wave and 3 min aggregation ( $r=-0.59 ; p<0.001$ both); the latter variable was negatively correlated to apo A-I $(r=$ $-0.55 ; p<0.01$ ) after 2 years.
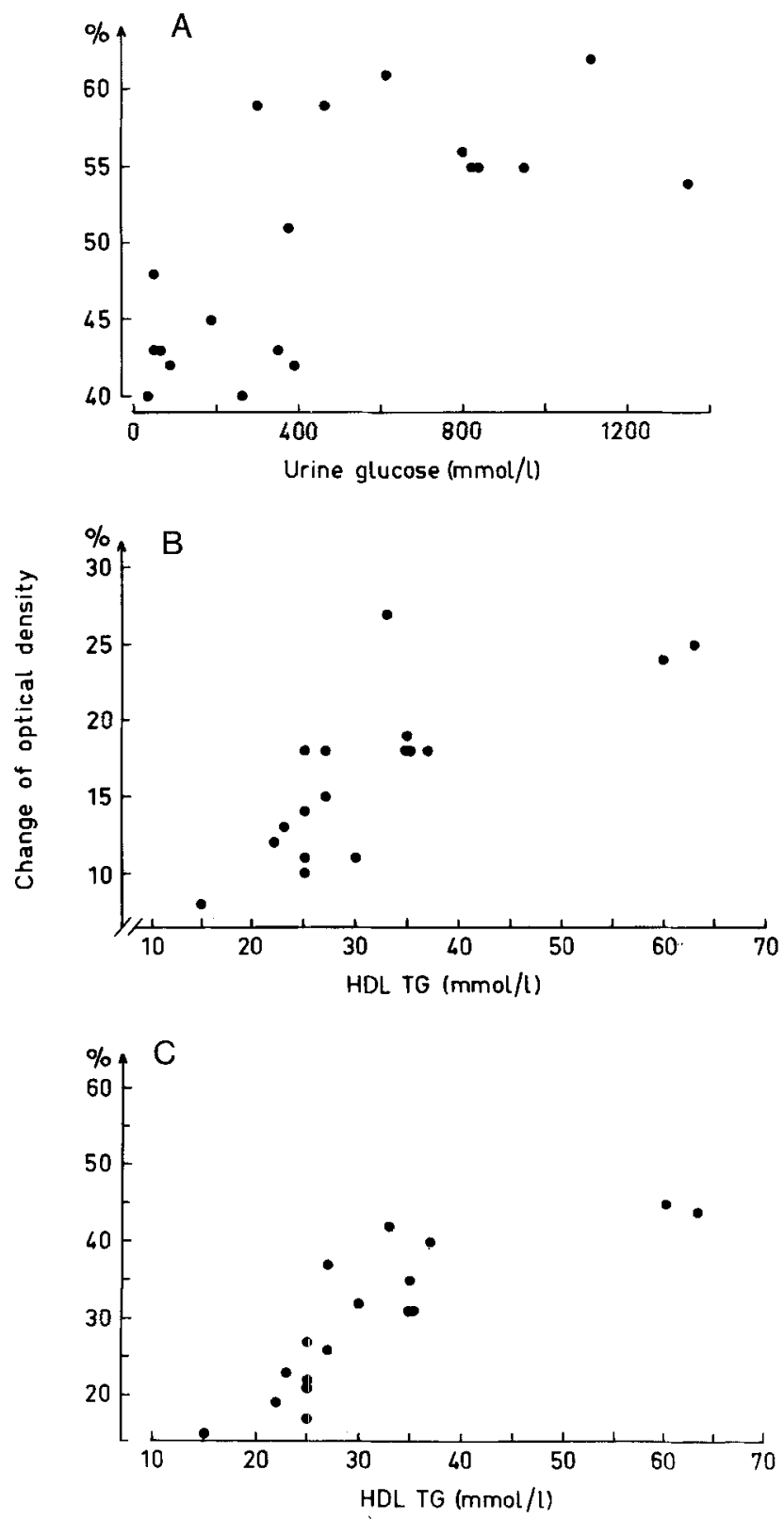

Fig. 5 A-C. High-density lipoprotein triglyceride (HDL TG) and $24 \mathrm{~h}$ urinary glucose excretion in relation to the primary wave aggregation induced by adenosine diphosphate (ADP) in different doses on admission (A. ADP $3.3 \mu \mathrm{mol} / 1, r=0.67 ; p<0.01$, B. ADP $0.55 \mu \mathrm{mol} / \mathrm{l}$, $r=0.78 ; p<0.001$, C. ADP $1.1 \mu \mathrm{mol} / 1, r=0.88 ; p<0.001)$

In the control group no significant correlation was found between platelet aggregability and any lipoprotein lipid variable.

\section{Discussion}

To our knowledge this is the first study on in vitro platelet aggregability in children with newly diagnosed Type 1 diabetes. Furthermore, no population-based prospective study has been undertaken in which the changes in platelet sensitivity to aggregating agents over time have been evaluated with concomitant investiga- 
tions of vascular dysfunction and metabolic changes in Type 1 diabetes. We made a new and unexpected finding of a decreased sensitivity to collagen-induced aggregation on admission, before the very first insulin injection. The aggregating capacity improved slowly and at a diabetes duration of one year the sensitivity to collagen was normalised. This should be compared with the findings in cross-sectional studies on adult populations with long-standing Type 1 diabetes [4-6, 9, 30], and also in our earlier study in children with an Type 1 diabetes duration of 2-8 years [25] of enhanced aggregability to low-dose collagen only. In a preliminary analysis of the first patients we suggested a normal collagen aggregation on admission and hyperaggregability after 12 months [31]. The discrepancy with our present results is explained by a lower response to collagen in the control children used in the preliminary study. In that study historical, non-fasting control children were used, whereas in this study matched fasting peers were investigated in parallel at the time of 24 month follow up.

No correlation to measured changes in carbohydrate, protein, metal or lipid metabolism could explain the decreased collagen-induced aggregability on admission. It has been proposed that zinc augments collagen aggregation [32]. Serum zinc was low in the children with diabetes on admission. It could be speculated that the reduced response was related to the reduction in serum zinc. However, these two variables were not statistically correlated. Furthermore, zinc also augments ADP-induced aggregation [32], which was not reduced in the present study. Perhaps, the circulating levels of catecholamines are increased in the untreated newly diagnosed children and a consequent down-regulation of alpha-adrenergic binding sites on the platelet membrane results in a decreased aggregability in response to collagen $[33,34]$. An alternative hypothesis is a disturbance of collagen adhesion to the outer surface of the platelet membrane and/or a defect in signal transmission and in activation of phospholipases $\left(\mathrm{A}_{2}\right.$ or $\left.\mathrm{C}\right)$, resulting in reduced metabolism of $\mathrm{AA}$. to thromboxane $\mathrm{A}_{2}[35]$. This possibility is supported by the finding of normal high-dose collagen-induced aggregation (3 min) which is independent of the AA pathway [36]. A decreased aggregability on admission could be an advantage, since dehydration and catecholamine release might increase the risk of acute rheological disturbances and acute thrombus formation in the circulation.

Another finding in this study was the increased platelet aggregability in response to low-dose ADP and AA. This platelet aberration in the newly diagnosed children with Type 1 diabetes was small, however, and was not significantly different from that in control children at 6,12 or 24 months. It corresponds quite well with the finding in adults with long standing Type 1 diabetes and vascular complications [4-7] and also with our observations in children with diabetes of 2-8 years duration [25]. The present study also demonstrates that platelet hyperreactivity can be normalised, at least in the first year of the disease.

ADP-induced aggregation on admission was highly statistically correlated to the increase in lipoprotein lipid fractions, which is part of the deterioration of carbohydrate and lipid metabolism in the insulin-deficient newly diagnosed diabetic patients. This correlation was also found for urinary glucose excretion during the first $24 \mathrm{~h}$, which is also a measure of the ongoing catabolism. The strong correlations between ADP aggregability and changes in lipoprotein lipid fractions and carbohydrate metabolism indicate that the metabolic derangement due to insulin deficiency occurs in parallel with platelet dysfunction [23], but changes in the lipid composition might also have a direct effect on the platelet membrane. Hyperlipoproteinaemia and incorporation of high concentrations of cholesterol in platelet membranes increases platelet aggregability $[16,17,37]$. The fatty acid composition of platelet nembrane phospholipids, dietary enrichment with unsaturated fats and the serum lipid composition have all been shown to be of importance for platelet function [18-21, 25, 38, 39]. Optimal treatment of Type 1 diabetes includes normalisation of carbohydrate and lipid metabolism, which also favourably reduces the hyperreactivity of platelets.

The difference in platelet aggregation between Type 1 diabetic and control children could not be explained by any difference between sex or age groups, but was a generalised finding. With the exception of the strong correlation between the hyperlipoproteinaemia on admission and the increased ADP sensitivity at that time, no obvious single biochemical changes can explain the results found in this studly. Even if the most speculative finding was the alteration of platelet aggregability on admission, the most important practical conclusion is probably that conventional insulin treatment is satisfactory from the point of view of normalisation of platelet sensitivity during the first two years. As we found in another part of this prospective study [40] that some aspects of vascular function deteriorated after two years in the same group of patients with now seemingly completely normal platelet aggregability, the early decrease in vascular reactivity could not have been due to primary changes in the platelets, at least not to changes influencing the tendency to aggregate.

The findings in the present study support the hypothesis that changes in platelet aggregability are secondary or late events and do not explain the early vascular dysfunction in vivo. Platelet hyperreactivity may play a role later as part of a vicious circle in the development of diabetic angiopathy, where an increased serum concentration of von Willebrand factor, a decreased capacity for prostacyclin formation in the endothelial cells and disturbed plasminogen activation and fibrinolysis promote platelet adherence and aggregation, vasoconstriction, and release of platelet derived growth stimulating factors. This indicates that platelet abnormalities together with a disturbance of lipid metabolism 
may be relevant for the progression of the macroangiopathy rather than for the microangiopathy of diabetes mellitus.

Acknowledgements. This study was made possible by grants from the Nordic Insulin Foundation, the Swedish Diabetic Association and Hoechst Diabetes Foundation.

\section{References}

1. Colwell JA, Winocour PD, Halushka PV (1983) Do platelets have anything to do with diabetic microvascular disease? Diabetes 32 [Suppl. 2]: 14-19

2. Schernthaner $G$, Sinzinger $H$, Silberbauer $K$, Freyler $H$, Muhlhauser I, Kaliman J (1981) Vascular prostacyclin, platelet sensitivity to prostaglandins and platelet specific proteins in diabetes mellitus. Horm Metab Res 33 [Suppl.1]: $33-43$

3. Ross R (1986) The pathogenesis of atherosclerosis - an update. $N$ Engl J Med 314: 488-500

4. Halushka PV, Lurie D, Colwell JA (1977) Increased synthesis of prostaglandin-E-like material by platelets from patients with diabetes mellitus. N Engl J Med 297: 1306-1310

5. Kwaan HC, Colwell JA, Cruz S, Suwanwela N, Dobbie JG (1972) Increased platelet aggregation in diabetes mellitus. J Lab Clin Med 80:236-246

6. Sagel J, Colwell JA, Crook L, Laimins M (1975) Increased platelet aggregation in early diabetes mellitus. Ann Int Med 82: 733-738

7. Johnson M, Harrison HE, Raftly AT, Elder JB (1979) Vascular prostacyclin may be reduced in diabetes in man. Lancet I: 325-326

8. Gerrard JM, Stuart MJ, Rao GHR, Steffes MW, Mauer SM, Bronn DM, White JG (1980) Alteration in the balance of prostaglandin and thromboxane synthesis in diabetic rats. J Lab Clin Med 95: 950-958

9. Silberbauer K, Schernthaner G, Sinzinger H, Piza-Katzer H, Winter M (1979) Decreased vascular prostacyclin in juvenileonset diabetes. N Engl J Med 300: 366-367

10. Paton RC (1979) Platelet survival in diabetes mellitus using an aspirin labelling technique. Thromb Res 15: 793-802

11. Burrows AW, Chavin SI, Hockaday TDR (1978) Plasma-thromboglobulin concentrations in diabetes mellitus. Lancet I: 235-237

12. Halushka PV, Mayfield R, Colwell JA (1985) Insulin and arachidonic acid metabolism in diabetes mellitus. Metabolism 34: 32-36

13. Harrison HE, Reece AH, Johnson M (1978) Decreased vascular prostacyclin in experimental diabetes. Lif Sci 23:351-355

14. Almér L, Nilson IM (1975) Fibrinolysis in diabetes mellitus. Acta Med Scand 198: 101-106

15. Almér L, Pandolfi M (1976) Fibrinolysis and retinopathy. Diabetes 25 [Suppl. 2]: $807-810$

16. Shattil SJ, Anaya-Galindo R, Bennet J, Colman RW, Cooper RA (1975) Platelet hypersensitivity induced by cholesterol incorporation. J Clin Invest 55: 636-643

17. Lees RS, Carvalho ACA (1978) Hypercholesterolemia and platelets. Adv Exp Med Biol 104: 301-308

18. Kalofoutis A, Lekakis J (1981) Changes of platelet phospholipids in diabetes mellitus. Diabetologia 21: $540-543$

19. Hornstra G (1973) Dietary fats and arterial thrombosis. Haemostasis $2: 21-52$

20. O'Brien JR, Etherington MD, Jamieson S, Vergroesen AJ, Ten Hoor F (1976) Effect of a diet of polyunsaturated fats on some platelet-function tests. Lancet II: $995-997$

21. Needleman P, Whitaker MO, Wyche A, Watters $\mathrm{K}$, Sprecher $\mathbf{H}$, Raz A (1980) Manipulation of platelet aggregation by prostaglandins and their fatty acid precursors: pharmacological basis for a therapeutic approach. Prostaglandins 19: 165-181

22. Elin RJ (1980) Role of magnesium in membranes: erythrocyte and platelet function and stability. Magnesium in health and disease. Spectrum Publications, pp 115-124
23. Kobbah M, Vessby B, Tuvemo T (1988) Serum lipids and apolipoproteins in children with Type 1 (insulin-dependent) diabetes during the first two years of the disease. Diabetologia 31: 195-200

24. Virella G, Wohltmann H, Sagel J, Lopes-Virella MFL, Kilpatrick M, Philips C, Colwell J (1981) Soluble immune complexes in patients with diabetes mellitus: detection and pathological significance. Diabetologia 21: 184-191

25. Ewald U, Kobbah M, Vessby B, Tuvemo T (1983) Increased platelet aggregability in diabetic children: relation to serum lipid and fatty acid composition. Diabetologia $25: 382-385$

26. Ewald U, Tuvemo T, Rooth G (1981) Early reduction of vascular reactivity in diabetic children detected by transcutaneous oxygen electrode. Lancet I: 1127-1128

27. Born GVR (1962) Aggregation of blood platelets by adenosine diphosphate and its reversal. Nature 194: 927-929

28. Kylberg E, Ewald U, Tuvemo T, Gebre-Medhin M (1985) Dietary intake in Swedish diabetic children. Acta Paediatr Scand 320: 32-37

29. Kobbah AM, Hellsing K, Tuvemo T (1988) Early changes of some serum proteins and metals in diabetic children. Acta Paediatr Scand $77: 734-740$

30. Janka HU, Demmel $\mathbb{P}$ (1981) Influence of metabolic control on platelet functions in diabetes mellitus. Horm Metab Res 11 [Suppl.]: 29-33

31. Kobbah M, Ewald U, Tuvemo T (1985) Platelet aggregation during the first year of diabetes in childhood. Acta Paediatr Scand [Suppl.] 320: 50-55

32. Heyns AP, Elder A, Yarom R, Marx G (1985) Zinc-induced platelet aggregation is mediated by the fibrinogen receptor and is not accompanied by release or by thromboxane synthesis. Blood 66: 213-219

33. Chung YH, Knapp DR, Halushka PV (1978) The effects of alpha adrenergic agents on human platelet aggregation. J Pharm Exp Therap 208: 366-370

34. Corby DG, O'Barr TP (1981) Decreased alpha-adrenergic receptors in newborn platelets: causes of abnormal response to epinephrine. Dev Pharmacol Ther 2: 215-225

35. Mackie J, Pittilo RM (1985) Vascular integrity and platelet function. Int Anesth Clin 23:3-21

36. Best LC, Holland TK, Jones PBB, Russell RGG (1980) The interrelationship between thromboxane biosynthesis, aggregation and 5-hydroxytryptamine secretion in human platelets in vitro. Thrombos Haemostas (Stuttgart) 43: 38-40

37. Micic J, Nesovic M, Djordjevic P, Micic D, Popovic M, Jancic M (1979) Plasma triglyceride levels and platelet aggregation in diabetes mellitus. In: Waldhäusl W, Alberti KGMM (eds) Abstracts: 10th Congress of the IDF. International Congress series 481, Excerpta Medica, p 409

38. Seyberth HW, Oelz O, Kennedy T, Sweetman BJ, Danon A, Frölich JC, Heimberg M, Oates JA (1975) Increased arachidonate in lipids after administration to man: effects on prostaglandin biosynthesis. Clin Pharmacol Therapeut 18: 521-529

39. Dyerberg J, Bang HO (1979) Lipid metabolism, atherogenesis, and haemostasis in Eskimos: the role of the prostaglandin-3 family. Haemostasis 8: 227-233

40. Kobbah AM, Ewald U, Tuvemo T (1988) Impaired vascular reactivity during the first two years of diabetes mellitus after initial restoration. Diabetes Res 8: 101-109

Received: 30 January 1989

and in revised form: 5 June 1989

Dr. T. Tuvemo

Department of Pediatrics

Akademiska Hospital

S-75185 Uppsala

Sweden 